\title{
Biomaterials and Biological Parameters for Fixed-Prosthetic Implant-Supported Restorations: A Review Study
}

\author{
Aysooda Afshari $\left(\mathbb{D},{ }^{1}\right.$ Seyed Ali Mosaddad $\left(D,{ }^{2}\right.$ Mostafa Alam (D), ${ }^{3}$ Kamyar Abbasi $\left(\mathbb{D},{ }^{4}\right.$ \\ and Meshkat Naeimi Darestani $\mathbb{D D}^{5}$ \\ ${ }^{1}$ Department of Prosthodontics, Dental Research Center, Faculty of Dentistry, Tehran University of Medical Sciences, Tehran, Iran \\ ${ }^{2}$ Student Research Committee, School of Dentistry, Shiraz University of Medical Sciences, Shiraz, Iran \\ ${ }^{3}$ Department of Oral and Maxillofacial Surgery, School of Dentistry, Shahid Beheshti University of Medical Sciences, Tehran, Iran \\ ${ }^{4}$ Department of Prosthodontics, School of Dentistry, Shahid Beheshti University of Medical Sciences, Tehran, Iran \\ ${ }^{5}$ Department of Periodontics, Dental Research Center, Faculty of Dentistry, Tehran University of Medical Sciences, Tehran, Iran
}

Correspondence should be addressed to Meshkat Naeimi Darestani; meshkat_dnt@yahoo.com

Received 15 November 2021; Accepted 23 December 2021; Published 18 January 2022

Academic Editor: Alicia E. Ares

Copyright (c) 2022 Aysooda Afshari et al. This is an open access article distributed under the Creative Commons Attribution License, which permits unrestricted use, distribution, and reproduction in any medium, provided the original work is properly cited.

\begin{abstract}
Because of the increasing use of dental implants, dental practitioners should understand the treatment and nature of peri-implant diseases (PIDs). This disease is a serious problem of dentistry, regarding epidemiology and therapy. Due to the increase in the practice of implantology as well as the increased number of implants placed every year, the rate of PID has widely increased. Periimplant mucositis and peri-implantitis, gingivitis, and periodontitis are common clinical manifestations of the disease. PIDs are caused by chronic inflammatory processes in the tissues around an intraoral implant, with increasing incidence, and have become a health concern. Bacterial infections are involved in the pathogenesis of these diseases. The imbalance between the host response and bacterial biofilm results in tissue destruction. New challenges lie in the prevention, treatment, and diagnosis of PIDs. The aim of this overview was to focus on the nature of the disease itself, useful diagnostic criteria, common responsible bacteria, and the prosthetic effects of fixed restorations on the health of the periodontium since recognizing the parameters involved in the development of periodontal and PIDs will play a crucial role in preventing the progression and minimizing the complications of these diseases having a fixed prosthesis.
\end{abstract}

\section{Introduction}

Loss of teeth or part of a tooth due to caries and periodontal disease is one of the undeniable problems in today's society. Failure to replace a lost tooth over time has caused the condition of the remaining teeth to change, the coordinated function of the teeth gradually changing and causing many problems in chewing, speaking, beauty, health, and dental hygiene [1]. With restorations, large areas of missing teeth or crowns can be replaced [2]. However, successful treatment of patients by a dentist for the placement of fixed prostheses requires a series of knowledge. Plaque accumulation in fixed restoration can endanger the life of the tooth, and the importance of this issue is clear from the fact that the prevalence of microbial plaque is very high and exists in all age groups and social and economic classes [3]. Also, the accumulation of microorganisms and the formation of microbial plaque can lead to gingival resorption and periodontal degeneration and marginal caries and, consequently, tooth sensitization, crown looseness, and ultimately lead to periodontal disease [4]. The link between periodontal and host microbes is usually benign, but when certain bacterial species overgrow in the subgingival spaces, they can cause periodontal inflammation and destruction with loss of tooth connection and bone loss. In periodontitis, the onset of the disease is associated with tissue colonization by these pathogenic species [5]. The next stage is bacterial invasion or invasion of periodontal tissues by their pathogenic products, 
reactions of bacteria, and their materials with host cells, and this results in tissue destruction, directly or indirectly, causing periodontal destruction. Bacterial species must be able to colonize the subgingival area to produce virulence factors that can directly (by producing enzymes or toxins) or indirectly (by producing antigens and activators) lead to the onset of a destructive inflammatory reaction in individuals and periodontal tissue injury [6]. Plaque reduction, usually above and below the gingival margin, can be a major factor in preventing periodontal disease and caries [7]. Plaque formation in fixed restorations is very important, so the use of appropriate materials to prevent periodontal disease is effective [8]. Also, because implants are prone to biofilminduced inflammatory diseases, it is necessary for the dentist to perform examinations using clinical indexes. Dental implants biological complications include plaque-related diseases, and the clinical manifestations are peri-implant mucositis and peri-implantitis, gingivitis, periodontitis [9], and non-plaque-related conditions near dental implants, such as mucosal hyperplasia, implant mucosal recession, lesions caused by trauma, and different nonspecific clinical diseases [10]. Diagnosis of such plaque-induced and nonplaque-related peri-implant diseases is associated with plaque-related active infection, for example, bleeding on probing, radiographic bone loss, exudate/suppuration, and increasing the depth of probing pocket. The prevalence rate of peri-implant mucositis and peri-implantitis has been reported to be nearly $43 \%$ (range $19 \%-65 \%$ ) and approximately $22 \%$ (range: $1 \%-47 \%$ ), respectively $[11,12]$.

Generally, bacterial virulence factors are challenging for the host for mounting a response for minimizing the harmful impacts of the bacteria or byproducts of them. These factors are toxins releasing by living bacteria and also cell wall constituents of the bacteria as well as cell contents releasing on cell death. Although there are many species that are considered indigenous for the oral cavity, some species are linked to caries and some certain other species, such as Prevotella intermedia, Actinobacillus actinomycetemcomitans, and Porphyromonas gingivalis, are involved in gingival inflammation and periodontitis $[13,14]$. Nonetheless, the host reaction is a crucial factor in initiation/ progression of the disease since all sites colonized via inflammation-associated bacteria certainly are not inflamed. Thus, the host response against a tooth/restoration or abutment/restoration interface should be realized and is more important compared to only measurement of the levels or presence of some bacterial species [15].

The aim of this review study was to gather conclusive information on diagnostic criteria for peri-implant diseases and the effect of fixed restorations and cementation on the health of the peri-implant tissues.

\section{Prosthetic Factors}

2.1. Type of Restoration. It is demonstrated that crowns that have intracrevicular margins, made of several traditional and new biomaterials, result in desirable microbial and gingival responses while supporting by either titanium implant abutments or natural teeth [15]; nonetheless, the zirconia crowns can exhibit the least marginal gingival inflammation [16] despite the fact that there have been no differences between porcelain and ceramic fused to metal restorations on periodontal health [17].

2.1.1. Porcelain-Fused-to-Metal (PFM). Today, one of the most popular and usable restorations is ceramic metal restoration, which combines the power and precision of metal casting with the beauty of porcelain. Porcelain-fusedto-metal (PFM) has long been used in clinical practice and is therefore considered the standard material for implantsupported restorations [18]. This type of infrastructure provides sufficient power and satisfactory aesthetic results. PFM crowns are considered the golden standard for repairing damaged teeth. A survey of 80 dentists found that $70 \%$ of them used PFM crowns to restore patients' posterior teeth. Also, in recent years, the demand for crowns that look natural has increased because ceramic materials have a high degree of beauty [19]. PFM crowns are more beautiful than previous metal coatings but have a shorter life and strength. It also has more strength but less beauty against ceramic coatings. PFM crowns last longer than all-ceramic veneers and less than metal veneers. Other advantages include high strength, beauty, and more acceptable cost than zirconia and all-ceramic coatings [20]. PFM crowns can also be used for front and posterior teeth, even bridges and implants. PFM is resistant to abrasions and cracks and is also recommended for people who grind or harden their teeth because PFM is more durable than other dental crowns [21].

2.1.2. Monolithic Zirconia. Zirconia is a white alloy used in the place of gray metal and is the basis of bridges and prosthetic dentures. Zirconia veneers are used to enhance the beauty of yellow, discolored, and incurable teeth with methods such as bleaching, and zirconia veneers are also used to treat congenital discoloration, cleft palate, broken teeth, and decayed teeth [22]. Zirconia veneer is also used as a bridge or veneer for molar teeth, anterior teeth, and as a treatment for the smile line. The monolithic zirconia crown has high flexural strength and shows high fracture resistance in the posterior region [23]. Because protective screw implants can also be made from integrated zirconium, evaluating the clinical results of this type of restoration is invaluable. The extraordinary strength of the integrated zirconia is due to its diamond-like structure [24]. This material does not need any other metal to increase strength and is resistant to abrasion and unbreakable. However, there are many types of zirconia ceramic systems available [25]. But only three of them are used in dentistry, which include glass-infiltrated zirconia-toughened, magnesium cationdoped partially stabilized zirconia (Mg-PSZ), and yttrium cation-doped tetragonal zirconia polycrystals (3Y-TZP) [26].

Zirconia-based restorations promise a great alternative to metal-ceramic restorations. Both fully sintered and semisintered zirconia products appear to be clinically acceptable. Adaptation of zirconia frameworks made with CAM/CAD technique is clinically acceptable. From the 
point of view of resistance fracture, fixed restorations of the zirconia particle are capable of withstanding occlusal physiological forces in the posterior region [27]. Clinical evaluations have shown that the clinical success of single restorations and zirconia bridges is excellent. It is similar to metal-ceramic restoration in terms of tooth preparation and cementing. Recently, surface preparation using simultaneous abrasion particle borne air and composite resin containing MDP-10 seems to be suitable for zirconia bonding. Despite the excellent clinical results in short-term research, we still need more clinical and laboratory studies to have long-term information about subzirconia restorations [28].

\subsection{Type of Cement for Cementation}

2.2.1. No Cement (Screw-Type Restorations). Unlike cement teeth restorations, screw-type restorations use screws to hold the teeth in place, which has several key advantages, including the ease of managing screw-retained reconstructions in the event of technical or biological complications, as crowns can be easily removed from the implant for further treatment, cleaning, or preparation. And, when removing the crown, the teeth are not damaged. Screw-type restorations are at a higher level in terms of implant hygiene than cemented dental restorations [29]. Since the adhesive coatings which are attached to the implant are more likely to cause infection, inflammation, and even bone loss, and inflammation often occurs when some adhesive leaks around the gum line and causes allergies. Therefore, it seems that screw-retained restoration is more desirable in terms of the long-term stability of the implant as well as the tissues around the implant and the implant infrastructure [30,31].

2.2.2. Temporary Cement. The decision to use temporary cement versus permanent cement is made based on the amount of retention required. In the case of implant-based prostheses, the desirability of recyclability, ease of removal and cleaning of cement from the abutment, and the amount of retention required, affects the choice of cement type [32]. The tensile strength of temporary cement must be such that they can withstand horizontal and vertical forces during operation, but they must also be weak enough to allow the prosthesis to be removed without damaging the abutment or implant [33]. When using cement, an important issue is the removal of cement residues, which have been reported to cause peri-implantitis when not removed properly [34]. At the time of delivery of the final implant prosthesis, the prosthesis is often cemented with temporary cement. The temporary cement must be fully solidified and provide a suitable and sufficient grip for the restoration to be able to hold the function properly [35]. The use of implant-based prostheses with cement retention is increased due to the similarity [36] of restoration methods for natural teeth, optimal occlusal adaptation, aesthetic enhancement, create disabled matching, ease of operation, low cost, disabled proper casting, less likely porcelain fracture, gradual loading, [37] reduced crystal bone resorption, and [38] role as a shock absorber. The biggest drawback of the cement retaining coating technique is the lack of a reliable average [39] for retention. Another problem is the possibility of problems due to the inability to remove excess cement from the implant margin, which causes severe periodontal disease in $80 \%$ of cases [40]. Materials mentioned as temporary cement in dental sources include type I zinc oxide eugenol cement (ZOE) or unmodified ZOE cement, zinc oxide without eugenol (eugenol-free $\mathrm{ZnO}(\mathrm{EF}-\mathrm{ZnO})$ ), and compound dimethacrylate. Today, zinc oxide compounds are the most widely used in this field and are generally divided into two types: zinc oxide eugenol and zinc oxide without eugenol [41, 42].

Provisional cements are characterized by high solubility and exhibit poor tensile strength [43], which are advantageous while completing a provisional recementing or cementation a prosthesis that is linked to peri-implantitis [44]. Retrievability of prosthesis is possible for provisional cements [45, 46]. Nonetheless, cement-retained implantsupported prostheses possibly lose retention while using provisional cement. Based on a systematic review by Ma and Fenton, $17.6 \%$ loss of retention of cement-retained implantsupported prostheses happened while using provisional cements [47]. Table 1 addresses the characteristics of EF$\mathrm{ZnO}$ and $\mathrm{ZOE}$.

2.2.3. Semipermanent Cements. Adequate retention is provided by semipermanent cements for resisting repeated decementation, and they allow for retrievability. Zinc phosphate (ZnP) and glass ionomer (GI) are regarded semipermanent cements while using with cement-retained implant-supported prostheses [43, 49]. Semipermanent cements decrease the risk of decementation than provisional cements. When a cement's tensile strength is between provisional and permanent cements, it can be categorized as a semipermanent cement. GI and $\mathrm{ZnP}$ provide retrievability while using with zirconia or titanium abutments $[49,50]$. A systematic review by Wittneben and Bragger showed a decementation rate of $0 \%$ for cement-retained implantsupported prostheses than $\mathrm{ZnP}$ [51]. ZnP and GI characteristics are provided in Table 2.

(1) Glass Ionomer (GI). Glass ionomer cement has been used in dentistry for about thirty years. This cement is like silicate cement in appearance and workmanship and similar to polycarboxylate cement in terms of adhesion. The composition of glass ionomer cements is complex and diverse. Calcium fluor aluminosilicate is the main constituent of this cement [52]. The three main components of glass ionomer cement used in dentistry are silica $\left(\mathrm{SiO}_{2}\right)$, alumina $\left(\mathrm{Al}_{2} \mathrm{O}_{3}\right)$, and calcium fluoride $\left(\mathrm{CaF}_{2}\right)$, which, when bonded together, it forms a suitable glass structure for cement formation. In glass ionomer cement, the basis of the hardening reaction and the formation of cement is based on the acid-base reaction [53]. The glass ionomer hardening reaction is a long-lasting comet reaction that lasts up to one month after material replacement [54]. In fact, it can be said that glass ionomer is an unusual material with 
TABle 1: Provisional cements [48].

\begin{tabular}{|c|c|c|c|}
\hline Cement type & Characteristics & Pros & Cones \\
\hline $\mathrm{ZOE}$ & $\begin{array}{l}\text { (i) Bactericidal } \\
\text { (ii) Soluble } \\
\text { (iii) Radiopaque } \\
\text { (iv) Poor bonding with } \\
\text { titanium } \\
\text { (v) Lowest tensile } \\
\text { strength } \\
\text { (vi) High pH } \\
\text { (vii) Perfect marginal seal }\end{array}$ & $\begin{array}{l}\text { (i) Marked decrease in periodontal pathogens } \\
\text { (ii) Lack of residual cement, leading to low chance of peri- } \\
\text { implantitis } \\
\text { (iii) Easy detection of excess cement. } \\
\text { (iv) Excess cement is easily removed } \\
\text { (v) Appropriate for provisionalization } \\
\text { (vi) Biocompatible } \\
\text { (vii) Low level of bacterial microleakage }\end{array}$ & $\begin{array}{l}\text { (i) Gap generation at the } \\
\text { abutment - prosthesis interface } \\
\text { (ii) Repeated decementations }\end{array}$ \\
\hline $\begin{array}{l}\text { Eugenol-free } \\
\text { zinc oxide }\end{array}$ & $\begin{array}{l}\text { (i) Organic acid } \\
\text { alternatives for eugenol } \\
\text { (ii) Solubility } \\
\text { (iii) Poor tensile strength } \\
\text { (iv) Poor inflammatory } \\
\text { soft tissue factors }\end{array}$ & $\begin{array}{l}\text { (i) Hypoallergenic } \\
\text { (ii) Elimination of the adverse effects of eugenol on resin } \\
\text { polymerization when permanent cementation is } \\
\text { considered } \\
\text { (iii) Poor risk of peri-implantitis }\end{array}$ & $\begin{array}{l}\text { (i) Higher microleakage } \\
\text { (ii) Poor retention }\end{array}$ \\
\hline
\end{tabular}

TABle 2: Semipermanent cements [48].

\begin{tabular}{|c|c|c|c|}
\hline $\begin{array}{l}\text { Type of } \\
\text { cement }\end{array}$ & Characteristics & Pros & Cons \\
\hline $\mathrm{ZnP}$ & $\begin{array}{l}\text { (i) Lower tensile strength compared } \\
\text { to GI, but higher compared to EF- } \\
\mathrm{ZnO} \\
\text { (ii) Low viscosity } \\
\text { (iii) Lack of adhesion to prosthesis } \\
\text { or titanium } \\
\text { (iv) Highest elastic modulus } \\
\text { (v) During setting, has high } \\
\text { solubility } \\
\text { (vi) Lowest level of creep } \\
\text { (vii) Highest radiopacity than } \\
\text { various luting agents } \\
\text { (viii) Cost effective }\end{array}$ & $\begin{array}{l}\text { (i) Decreased risk of decementation } \\
\text { compared to provisional cements } \\
\text { (ii) Easy flow for better mechanical retention } \\
\text { (iii) High rigidity, making it appropriate for } \\
\text { regions subjected to high occlusal forces } \\
\text { (iv) Dimensionally stable, leading to no } \\
\text { generation of stress on full ceramic } \\
\text { prostheses } \\
\text { (v) Excess cement can be easily detected easy } \\
\text { removal of excess cement than GI cements } \\
\text { and resin } \\
\text { (vi) Inexpensive }\end{array}$ & $\begin{array}{l}\text { (i) Inappropriate for short prostheses or } \\
\text { abutments with elevated prosthetic } \\
\text { abutment gap } \\
\text { (ii) Insufficient marginal seal }\end{array}$ \\
\hline GI & $\begin{array}{l}\text { (i) Proper mechanical strength as } \\
\text { well as bonding to base metal alloys } \\
\text { (ii) Critical manipulation at setting } \\
\text { time } \\
\text { (iii) High material creep } \\
\text { deformation over time } \\
\text { (iv) High water absorption } \\
\text { (v) Low elasticity modulus } \\
\text { (vi) Radiopaque } \\
\text { (vii) An increase in retention over } \\
\text { time because of continued } \\
\text { polymerization } \\
\text { (viii) Cost effective }\end{array}$ & $\begin{array}{l}\text { (i) Proper retention } \\
\text { (ii) There are some brands (GC Fuji Temp } \\
\text { LT) radiographically }\end{array}$ & $\begin{array}{l}\text { (i) Insufficient moisture control at setting } \\
\text { time leads to high microleakage } \\
\text { (ii) Microcracks with extreme dryness at } \\
\text { setting time } \\
\text { (iii) No dimensional stability } \\
\text { (inappropriate for full lithium disilicate } \\
\text { ceramic crown) } \\
\text { (iv) Inappropriate in regions facing high } \\
\text { occlusal forces }\end{array}$ \\
\hline
\end{tabular}

excellent properties and is different from other materials. It is semitransparent like tooth porcelain and sticks to tooth tissue [55]. These materials adhere permanently to the enamel and dentin, which causes the seam between the material and the dental tissue to close almost completely, preventing the penetration of caries, thereby preventing secondary caries [56]. Recently, it has been reported that these substances have the property of releasing fluoride for a long time and can absorb fluoride when exposed to fluoride solution, thus inhibiting the progression of caries in adjacent tooth tissue [57]. In fact, glass ionomer cement has the approval and basic properties such as biocompatibility with dental pulp, the ability to chemically bond to enamel and dentin, and release fluoride, which can play an important role in inhibiting bacterial growth and caries progression [58]. The release of glass ionomer cement fluoride seems to be the most likely reason for the inhibitory effect on acid production. The availability of fluoride from glass ionomer cement is controlled by $\mathrm{pH}$, which is controlled by salivary phosphate and proteins [59]. In general, glass ionomers are widely used in the restoration of dental structures in clinical dentistry. 
(2) Zinc Phosphate (ZnP). Zinc phosphate cement was introduced in the year 1880 and has been used successfully in dentistry since then [60]. This cement is prepared by combining liquid phosphoric acid and powder containing zinc oxide and magnesium oxide. Although its use has declined with the introduction of other types of cement, this type of cement is still available in many countries [61]. Zinc phosphate cement has no chemical bond to dental structures and has medium compressive strength (62 to $101 \mathrm{MPa}$ ), low tensile strength (5 to $7 \mathrm{MPa}$ ), and high solubility $(0.36 \%)$. After mixing, its $\mathrm{pH}$ is low, and about 2 and after 24 hours, it reaches $5.5[62,63]$. Despite the low $\mathrm{pH}$ of this cement, it has been reported that it has no irritating effect on the pulp and it is biocompatible [64]. Due to the long history of using zinc phosphate cement, it is considered the golden standard of cement, and other types of cement are compared with it $[63,65]$. Increasing the $\mathrm{pH}$ over time in zinc phosphate cement and decreasing fluoride release in glass ionomer cement can be the reason for the decrease in antibacterial properties. Also, an increase in $\mathrm{pH}$ in zinc phosphate cement occurs faster than a decrease in fluoride release in glass ionomer, and this may be the reason for the lower antibacterial activity of zinc phosphate cement than in glass ionomer [66, 67]. During a study, the antibacterial properties of seven types of cement (including RMGI, GI, composite resin, zinc phosphate, polycarboxylate zinc, ZOE, and zinc noneugenol oxide) against Streptococcus mutans were investigated, and it was observed that zinc phosphate cement showed the strongest antibacterial activity immediately after mixing compared to noneugenol, eugenol, and resin cement [68]. Due to a passive fit of implant-supported fixed partial dentures (ISFPDs), an essential gap is observed between the intaglio and abutment of the retainer for preventing a pressure on the supporting implants. For $\mathrm{ZnP}$ retention on natural teeth, a thin film thickness can be favorable; however, it is not significant for implant-supported abutments. Due to metal-to-metal marginal and internal gaps, $\mathrm{ZnP}$ solubility is a liability. This gap makes the cement exposed to oral fluids. When using $\mathrm{ZnP}$ as definite cement in multiple unit ISFPDs, ZnP cement dissolution may be seen. The cement dissolution of one or more retainers in a multiple unit ISFPD results in the transferring of the occlusal load toward the remaining retained units. Also, rotational force of the cement-retained implants may be observed; thus, the parafunctional and occlusal loads would be borne through the abutment-retained implants. Therefore, there is a risk for loss of integration, detrimental rotation, and overloading. ZnP cannot be indicated for ISFPDs or splints. Cement dissolution in single units may only involve recementation, when patients do not aspirate or swallow the crown [69].

\section{Periodontal Factors}

3.1. Peri-Implant Mucositis and Peri-Implantitis. An inflammatory lesion can be developed when a bacterial biofilm develops near a dental implant [70, 71]. Peri-implant diseases as infectious diseases are caused by developing a bacterial biofilm attached to the surface of implant that affects the implant supporting tissues and is very similar to periodontitis $[72,73]$. However, the teeth and dental implants are different because teeth are characterized by the periodontal ligament including blood vessels as well as lymphatic channels. On the contrary, titanium dental implants are directly attached to the bone, which has been named as "osseointegration."

3.2. Risk Factors. Placing implants in the maxilla in male subjects and also cases who had a history of periodontitis is considered as risk indicators $[74,75]$. There are many other risk factors linked to the development of PID, like smoking, poor oral hygiene and excess of cement. The occlusal overload role as a single risk factor has not well identified, in spite of the indications suggesting that overload alone is not linked to tissue destruction as well as PID without plaque. Occlusal overload possibly is involved when associated with preexisting inflammation or plaque accumulation. Nonetheless, the information is not clear $[76,77]$.

3.3. Etiology and Diagnosis. An imbalance between the host defense and the bacterial load causes peri-implant disease (PID) [9]. To prevent and appropriately handle complications, the proper diagnosis of peri-implant conditions (periimplant mucositis, peri-implant health, and peri-implantitis) is of great importance [78]. Regular and routine examinations of cases with dental implants are used along with approved procedures for maintaining periodontal health. Detection of biological complications at a reversible and early stage can facilitate effective interception and prevent the progression of peri-implant complications [10].

Heitz-Mayfield defined the criteria for an accurate diagnosis of PID [79]. According to them, radiographic assessment and probing were proposed as the primary diagnostic tools.

A World Workshop on Periodontology (2018) reported bleeding on gentle probing as the main clinical characteristic of peri-implant mucositis, and it was stated that swelling, erythema, and/or suppuration may also be found. Periimplantitis sites show the same clinical signs of inflammation, and also there is an increase in the recession and/or probing depth of the mucosal margin and also radiographic loss of bone compared to previous examinations. The following definitions were obtained from a review article by Renvert et al. $[80,81]$ and a consensus report by Berglundh et al. [82].

The following items are required for the diagnosis of peri-implant health:

(1) No clinical signs of inflammation

(2) No suppuration and/or bleeding on gentle probing

(3) The absence of an increase in probing depth compared to previous examinations

(4) No bone loss beyond crestal bone-level alterations caused by initial bone remodeling

Diagnosis of peri-implant mucositis requires the following: 
(1) Presence of suppuration and/or bleeding on gentle probing with/without an increase in probing depth in comparison with previous examinations

(2) No bone loss beyond crestal bone-level alterations caused by primary bone remodeling

Diagnosis of peri-implantitis needs the following:

(1) Bleeding and/or suppuration on gentle probing

(2) An increase in probing depth in comparison with previous examinations

(3) Bone loss beyond crestal bone-level alterations caused by primary bone remodeling

\subsection{Clinical Parameters}

3.4.1. Bleeding on Probing (BOP). Insertion of the probe to the depth of the envelope will cause bleeding if the gums are inflamed and the epithelium of the envelope is atrophic or injured. Noninflammatory areas rarely bleed. In most cases, bleeding during probing, as a sign of inflammation, is detected earlier than gum discoloration [83]. However, nonbleeding discoloration may be observed during the probe [84]. Depending on the severity of the inflammation, the bleeding can vary from a thin red line around the gingival sulcus to severe bleeding [85]. After successful treatment, the bleeding stops during the probe [86]. The Gingival Bleeding Index is used to screen for gingivitis and periodontitis, determine the prevalence of the disease, evaluate treatment outcomes, and determine disease progression [87]. BOP, if performed as standard, is a reliable indicator of the health status of periodontal tissues [88]. To test for bleeding during probing, the probe is carefully inserted into the depth of the envelope and gently moved laterally along the edge of the envelope wall. Sometimes the gums bleed immediately after the probe comes out; in some other cases, bleeding occurs after a few seconds [89]. Therefore, the clinician should reexamine the bleeding 30 to 60 seconds after probe. As a single test, bleeding during the probe is not a good indicator of the progression of attachment loss. However, its absence is an excellent indicator for predicting the stability of periodontal status [86]. Bleeding during probing can be a good indicator of progressive attachment loss when bleeding has occurred in several areas of the progressive disease [90]. No BOP can indicate healthy soft tissue and a decreased chance of disease progression/development [91]. A diagnosis of peri-implant health could predict maintenance of implants over 20 years or more [92]. Peri-implant disease can be prevented by early detection of inflammation around implant. The BOP presence can suggest soft tissue inflammation and is used clinically for distinguishing between peri-implant mucositis or peri-implantitis and peri-implant health [11].

3.4.2. Clinical Attachment Loss (CAL). The CAL is one of the primary symptoms of periodontal disease. Attachment loss is the apical migration of the dentogingival junction-periodontal attachment apparatus-the result of an inflammatory response due to the formation of oral biofilm (Figure 1) [93]. The junction of teeth and gums consists of epithelial junctions and connective tissue junctions. The size of the junction of the teeth and gums is called the biological width, and the average is $2.04 \mathrm{~mm}$ [94]. Under healthy conditions, without loss of adhesion, connective tissue connectivity at the coronal side begins at the cementoenamel junction (CEJ), and epithelial connectivity is more coronal than connective tissue connectivity. In cases where there is a loss of adhesion, CEJ becomes apparent [95].

CAL measures the amount of adhesion loss that occurs by reference to CEJ. The extent of clinical adhesion loss is the distance between the CEJ and the depth at which gingival crevice probing is possible. When the gingival margin is on the anatomical crown, CAL is the result of subtracting the distance between the gingival margin and the CEJ from the probing depth. If these two values are equal, the CAL will be zero [96]. CAL is equal to the probing depth when the gingival margin is on the CEJ. When the gingival margin is at the apical CEJ, the CAL is greater than the probing depth, so in this case, the CAL (distance between the CEJ and the depth of the gingival groove with the possibility of probing) is equal to the sum of the gingival resorption values and the probing depth. Drawing the position of the gingival margin on the periodontal chart at the point where the probing depths are recorded helps to clarify this important point [97].

In many dental office management software, CAL is calculated automatically by adding the values of analysis and probing depth. This calculation is only accurate if both the depth of probing and the amount of analysis are entered correctly in the software [98]. When the amount of analysis is not entered into the software, many assume that the CEJ is flush with the gingival margin and assume that the amount of clinical adhesion loss is equal to the depth of probing. This calculation is not necessarily correct because many clinicians do not enter any value into the software when the CEJ is subclavian and invisible [99]. Thus, the automatically calculated CAL should be reviewed and criticized before being used to aid in diagnosis.

3.4.3. Probing Depth (PD). There are two different types of envelope depth, biological or histological depth, and clinical or probing depth. Biological depth is the distance between the gingival margin and the base of the gingival groove (the coronal end of the junctional epithelium) and can only be measured by very precise histological sections [100]. Probing depth is the distance between the gingival margin and the depth of the groove with the possibility of probing. The degree of penetration of the probe depends on the shape and size of the probe tip, the force used to insert the probe, the strength of the tissue, the convexity of the crown, and the degree of inflammation of the tissue [101]. The depth of probing is generally less than $3 \mathrm{~mm}$ in gingival health and greater than $3 \mathrm{~mm}$ in the presence of inflammation. In human periodontal pockets, the tip of the probe is inserted into the most coronal fibers of healthy and intact connective tissue attachments [102]. In a periodontal pouch, a probe 


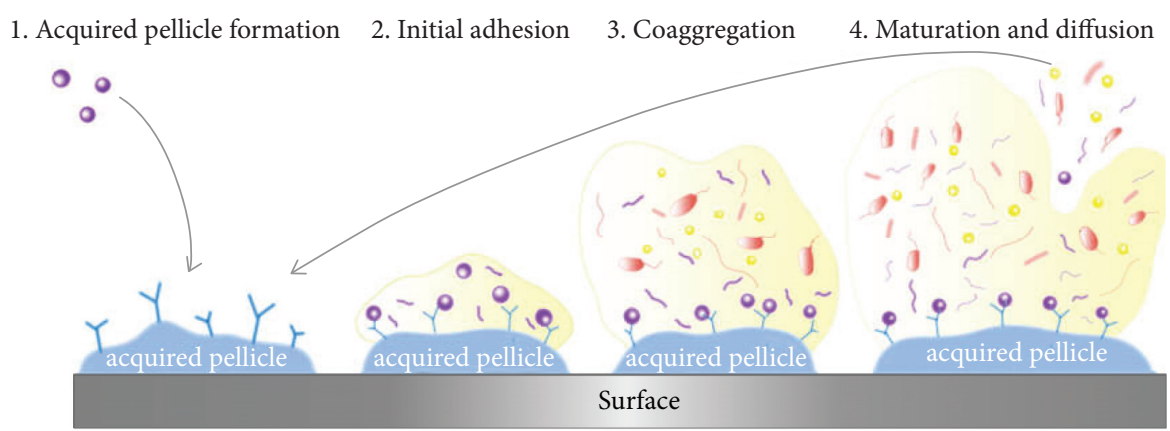

Figure 1: The formation stages of biofilm [177].

about $0.3 \mathrm{~mm}$ apically from the junctional epithelium penetrates into the connective tissue [103]. This is important in assessing the difference in probing depth before and after treatment, as reduced probe penetration is more likely to be due to a reduced inflammatory response, rather than attachment gain [104]. The depth of probing may change at different times, even in patients with untreated periodontal disease, due to changes in the position of the gingival margin. Therefore, the depth of probing may have nothing to do with connective tissue connections [105].

Probing depths around implants are associated with the soft tissue height around the implant as well as the primary placement of the implant. The pocket depth is associated with where and how deep the implant is located in the jawbone. Therefore, peri-implant tissue health exists surrounding implants with different levels of bone support. Probing depths is needed to be dependent on reference to the depths while placing the implants in the oral cavity after the healing process [106].

A force of $0.25 \mathrm{~N}$ is needed for probing to prevent damage to the peri-implant tissues and assess the presence of BOP, indicating the existence of inflammation in the peri-implant mucosa. It can predict no tissue support. PD should be examined regularly to detect BOP and suppuration and also to indicate an increase in depth, which is usually dependent on the supporting bone and loss of attachment [9]. Monitoring alterations in probing depth should be done for the diagnosis of peri-implant conditions. Increasing pocket probing depth indicates disease progression. The design of the prosthetic reconstruction may make probing at implants difficult. It is very important that the prosthetic reconstruction allows both easy access for oral hygiene measures and access for accurate probing around the implant. It should be noted that there is a major risk for underestimating the probing depths at implants when probing is performed with the prosthetic reconstruction in place [107].

3.4.4. Suppuration. Suppuration is caused by inflammation associated with neutrophil cell death in the soft tissues around the infected implants. Suppuration is a diagnostic factor for peri-implant disease [108], and its presence indicates the need for further evaluation and treatment.
3.4.5. Radiographic Evaluation. Taking a radiograph is recommended in the presence of clinical signs of disease (suppuration, BoP, and deepening pocket), for evaluating the presence of bone loss. For measuring bone loss at the site of implant, the bone height should be compared between visits and also when the implant healed in relation to baseline conditions. Bone loss around dental implants can be measured through radiographs. Long-cone parallel radiographic projection methods can evaluate crestal bone-level alterations [109].

Several variations in the extent of bone loss required for making a definition of peri-implantitis have been suggested [79]. An effective working threshold to diagnose periimplantitis can be bone loss at implants $2 \mathrm{~mm}$ from the considered marginal bone level after early remodeling, which is called "biological bone remodeling" [109, 110]. When the implant type is known, the length of the implant thread pitch can be identified, which makes it possible to calibrate distances from the implant platform to bone-level contact $(\mathrm{mm})$. In case of no previous radiographs, a bonelevel distance of more than or equal to $3 \mathrm{~mm}$ apical to the most coronal part of the intraosseous part of the implant can indicate peri-implantitis. Therefore, it is essential to record radiographic and clinical data following prosthesis installation of implants for securing baseline criteria regarding the differential diagnosis of peri-implant diseases [109-111].

It is essential to take radiographs regularly for assessing the possible elevation in bone loss. Therefore, there is no settled, official classification to distinguish various levels of severity of PID, like the classification for periodontal disease; however, in 2012, Froum and Rosen proposed a classification [112] (Table 3).

For estimating advanced peri-implantitis defects in lingual, facial, and proximal bony lesions, cone beam computed tomography seems an accurate diagnostic tool [113]. In case of development of a radiographically radiolucent periapical lesion shortly following implant placement when the bone is osseointegrated in the coronal part of the implant, it is called retrograde peri-implantitis. A fistula can be developed in some cases $[114,115]$.

3.4.6. Gingival Recession (GR). The gums are part of the orthodontic canal that acts as a strong barrier against the penetration of stimuli into the periodontal tissue while 
Table 3: Peri-implant disease classification.

\begin{tabular}{lc}
\hline Type & Characteristic \\
\hline Early & $\begin{array}{c}\text { PD greater or equal to } 4 \mathrm{~mm} \text { (suppuration and/or bleeding on probing) } \\
\text { Bone loss of smaller than 25\% of the length of implant }\end{array}$ \\
\hline Moderate & $\begin{array}{c}\text { PD greater or equal to } 6 \mathrm{~mm} \text { (suppuration and/or bleeding on probing) } \\
\text { Bone loss of } 25-50 \% \text { of the length of implant }\end{array}$ \\
\hline Advanced & $\begin{array}{c}\text { PD greater or equal to } 8 \mathrm{~mm} \text { (suppuration and/or bleeding on probing) } \\
\text { Bone loss of greater than 50\% of the length of implant }\end{array}$ \\
\hline
\end{tabular}

covering the cervical region of the teeth and the alveolar appendages of the mandible and upper jaw $[116,117]$. The normal position of the gums is $1-3 \mathrm{~mm}$ higher than the CEJ of the tooth, which moves to the CEJ over time $[118,119]$.

GR means moving of the edge of the gum from its normal position on the crown of the tooth to the lower levels relative to the CEJ [120]. Gingival resorption can be localized or diffuse and usually increases with age [121, 122]. GR occurs because of a combination of etiological and predisposing factors. Predisposing factors include keratinized gingival insufficiency, iatrogenic factors, bone fractures, and improper placement of the tooth in the dental arch [123]. Etiological factors include toothbrush damage, periodontal disease, ectopic frenum, and orthodontic treatment [124].

Some dental treatments can make the site more prone to gingival recession, such as preparation of dental incision under the gums, casting procedures in which the gums are removed, restorations, and veneers that are placed under the gums, and dentures that are not designed properly and the placement of the clasp, which increases the accumulation of plaque around the base tooth, causes GR [125]. However, one of the main causes of gingival recession is a gingival infection due to pathogenic bacteria after implantation, which can lead to implant destruction. When a gingival recession occurs, "envelopes" or gaps are created between the teeth and the gum line, making it easier to get the disease from existing bacteria. If left untreated, the supporting tissue and bone structures of the teeth can be severely damaged and can eventually lead to tooth loss [126].

3.5. Microbial Profile. The peri-implant biofilm bacterial composition was very similar to that of the neighboring teeth indicating that the microbial flora on natural teeth can be served as the biofilm generation reservoir around implants. Also, the biofilm microflora qualitative composition in periimplantitis was very similar to that of periodontitis indicating why cases suffering from active periodontal disease are more prone to peri-implantitis. To support this theory, Kocar et al. [127] assessed cases with partially edentulous and fully edentulous patients and reported that the peri-implant as well as periodontal sulci of partially edentulous patients were not different regarding the microflora and share the same periodontopathogenic species; however, none of these bacteria were detected in the peri-implant sulci or the alveolar gingiva in patients with complete edentulous. Also, the existence of nonperiodontal microbial species, like Candida albicans, Pseudomonas aeruginosa, Staphylococcus warneri, and Staphylococcus aureus, has been reported around diseased implants $[70,128,129]$.
3.5.1. Porphyromonas gingivalis ( $P$. gingivalis). Today, more than 700 bacterial species can be identified in samples taken from the oral cavity [130] $P$. gingivalis is a Gram-negative, immobile, saccharolytic, rod-shaped, forced anaerobic bacterium associated with the onset and progression of periodontal degradation. This bacterium is found in small amounts in the mouth of healthy people [131], and it can be harmful when it attaches to the tooth surface and, by covering the tooth surface, leads to the formation of a mixed biofilm, which eventually leads to the spread of bacteria to the gingival fungus and forms the periodontal pocket [132]. Inside it is crevicular fluid, which is an inflammatory secretory source of nutrients essential for the growth of $P$. gingivalis [133]. The bacterium has a capsule that protects it against phagocytosis, also has fimbriae (for adhesion) and vesicles, and is able to produce a number of virulence factors [130]. P. gingivalis is the first pathogen of chronic periodontitis and the second most common pathogen in invasive periodontitis. One of the reasons why this bacterium has attracted the most attention is its high ability to escape the immune response. It is also able to alter the immune response of the host, thus creating a favorable environment for its persistence and other pathogens [134]. This bacterium causes the destruction of periodontal tissues by creating a number of virulence factors and extracellular proteases such as fimbria, lipopolysaccharide, gingipain, which is one of the main causes of periodontal diseases [130]. Virulence factors of $P$. gingivalis play an important role in the formation of biofilm and oral microbial dysbiosis. It is also detectable in $85 \%$ of subgingival plaques in patients with chronic periodontitis [135]. It is believed that this bacterium (even when it is in low abundance) is able to induce chronic periodontitis [136]. It has also been shown that $P$. gingivalis is able to interact with Streptococcus gordonii to form dental plaque and binds to GAPDH and surface proteins on the surface of $S$. gordonii to form $P$. gingivalis biofilms on the tooth surface [137]. LPS is one of the most important components in the wall structure of Gram-negative bacteria, including the periodontal pathogen $P$. gingivalis [138]. $P$. gingivalis LPS plays an important role in pathogenesis in periodontal tissues. The virulence properties of $P$. gingivalis LPS is determined by its lipid A component. The host cells respond to $P$. gingivalis LPS lipid A and cause inflammatory responses in the gingival tissues, thereby creating a favorable environment for pathogens that lead to the progression of periodontal disease [139]. Finally, it can be noted that $P$. gingivalis leads to inflammation and loss of alveolar bone in several ways, including upregulation of TLR2 expression and proinflammatory cytokine, NF-кB pathway, the mitogenactivated protein kinase (MAPK) pathway [130, 139]. 
3.5.2. Treponema denticola (T. denticola). T. denticola is a Gram-negative, motile, anaerobic bacterium associated with periodontal lesions. This bacterium is more common in patients with severe periodontitis than in patients with healthy periodontitis or gingivitis [140]. This microorganism produces proteolytic enzymes that can break down immunoglobulins (IgG, IgM, and IgA) and complement factors. The bacterium attaches to host cells and tissues, as well as matrix proteins and collagen-binding proteins and collagens that act as barriers to bone regeneration [141]. It can also bind to other bacteria, including $P$. gingivalis or other bacteria involved in the periodontal formation, which can lead to bipolar and nutritional interactions. The high motility of this bacterium and the presence of proteolytic enzymes and cytolytic agents in it contribute to the possible invasive ability of treponemes [142]. As periodontal treatment progresses, the depth of individual pockets and the amount of inflammation as well as the treponemal population decrease. T. denticola can cause periodontal disease in several ways: activation of IL, bone resorption, an inhibitor of superoxide production by leukocytes, enhancement of collagen phagocytosis by gingival fibroblasts, a monocyte-dependent suppressor for human lymphocyte response, suppression of fibroblast proliferation [143, 144]. Since the amount of $T$. denticola in plaque samples collected from deep pockets of patients with severe periodontitis is higher than healthy people or people with moderate disease, so it can be concluded that there is a positive and significant relationship between $T$. denticola and severe periodontitis $[145,146]$. T. denticola, like $P$. gingivalis, is found mainly in the plaque below the gums and is found in periodontal pockets more than $4 \mathrm{~mm}$ deep. In a mouse study of periodontal disease, $T$. denticola infection was found to induce alveolar bone resorption $[147,148]$. It was later shown that acylated dual and triple synthetic lipopeptides, which preferentially activate the TLR2/6 and TLR2/1-dependent pathways, play a key role in stimulating alveolar bone loss in the mouse model [149].

$T$. denticola is involved in the expression of several virulence factors. Among them can be the major surface protein (Msp), chymotrypsin-like protease (CTLP), and cellassociated lipooligosaccharide. These factors facilitate the integration of $T$. denticola within oral dental plaque biofilms as well as promoting its adherence and subsequent invasion into the host's cells. Although T. denticola lacks a specific adhesive structure such as fimbriae, it is able to adhere to various surfaces of the oral cavity, including teeth, host soft tissue, and microbes in plaque biofilms by various other factors, including Msp, lipooligosaccharide, and CTLP $[150,151]$.

This bacterium is able to penetrate the epithelial cell by disrupting tight cell connections. This penetration is facilitated by CTLP and the outer membrane. The immunomodulatory activity of $T$. denticola, which is facilitated by Msp and CTLP, is involved in its pathogenicity, including being able to elicit a strong antibody response in adult patients with invasive periodontitis [152]. It also inhibits the chemotoxic activity of neutrophils and suppresses the properties of human peripheral mononuclear cells and fibroblasts. It can also be said that $T$. denticola exerts cytopathic activity against epithelial cells and fibroblasts that represent periodontal tissue, in which these cytopathic activities lead to vacuolization, membrane damage, cell detachment, loss of tight intercellular contact, inhibition of proliferation, and cytoskeletal rearrangements [153].

\subsubsection{Prevotella intermedia ( $P$. Intermedia). P. intermedia is} a short, immobile, Gram-negative, pathogenic anaerobic, rod-shaped bacterium with a rounded end. This bacterium has the ability to communicate with other oral bacteria. Among other things, it is able to communicate with Peptostreptococcus and lead to a dentoalveolar infection by increasing the virulence factor [154]. Various studies have shown that $P$. intermedia is associated with the incidence of acute necrotizing ulcerative gingivitis, pregnancy gingivitis, HIV-associated periodontal lesions, and periapical abscess [155]. In the oral cavity, $P$. intermedia, along with other pathogens, play an important role in the onset and subsequent development of polymicrobial periodontal disease. $P$. intermedia is visible in healthy and diseased periodontium, but its amount is higher in unhealthy periodontal than in healthy periodontal [156]. P. intermedia can be removed from odontogenic abscesses, saliva, the tongue, as well as subgingival sites of healthy and sick people [157]. According to a study by Maeda et al, the amount of $P$. intermedia in microbiological samples collected from the subgingival crevices or periodontal pocket was reported to be $71 \%$ in healthy individuals and $88 \%$ in patients with periodontal disease [158]. As we know, periodontal tissue destruction occurs mainly through cytokines and inflammatory proteinases released by immune cells in response to pathogens [159]. P. intermedia is able to destroy periodontal tissue through the expression of proinflammatory cytokines in human gingival epithelial cells and human periodontal ligament (hPDL) cells [160]. Also, MMPs produced by host cells, along with other proteinases, are responsible for the connective tissue destruction in periodontitis [161]. The results of a study by $\mathrm{Zheng} \mathrm{Wu}$ et al. show that $P$. intermedia leads to the expression of MMP-9 in hPDL cells [162]. In this way, it can also cause damage and destruction of periodontal tissue. It is also able to directly separate ECM components of the periodontium by proteinases and endotoxins and indirectly destroys periodontal tissues through one or more of the five host-destroying pathways, including MMP pathway, osteoclastic bone resorption, phagocytic pathway, PMNserine proteinase pathway, and plasminogen-dependent pathway [163]. Because the collagen degradation of unmineralized connective tissues and the organic component of bone in inflamed periodontal tissues is likely to be mediated by MMPs, $P$. intermedia plays an important role in the loss of connective tissue during progression by rapidly inducing MMP-9 expression [164].

\section{Discussion}

Replacement of missing teeth or part of a tooth that has been lost for various reasons has long been a problem in human 


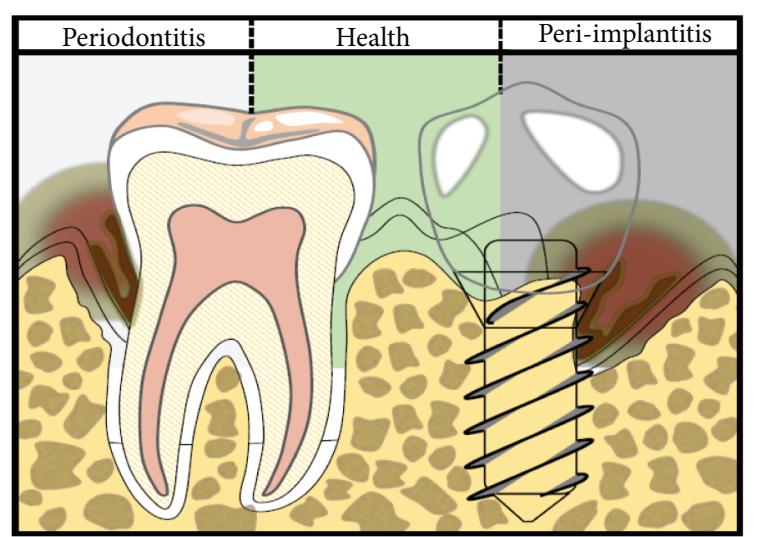

Figure 2: Periodontitis (left); peri-implant (right) [178].

societies that today can be compensated by using a variety of ceramic and metal castings or ceramic alone. But the successful implementation of such treatment requires compliance with a set of principles and methods of treatment [165]. And, the ultimate goal of the dentist is to perform proper restoration without damaging the healthy periodontal tissue $[166,167]$. Since hygiene is one of the most important conditions for proper restoration and attracting positive feedback from patients [168], the use of a material that reduces plaque accumulation can be an important treatment to prevent periodontal disease (Figure 2) [169]. The increasing acceptance of dental implants can be explained by further development in both technical and biological aspects. At present, patients and dentists have a wide range of techniques and reinforcements, types of implants, and artificial structures to choose from. In this regard, it should be noted that decisions about the types and materials of superstructures can have a significant impact on the outcome of implant treatment. There are basically two types of infrastructure stabilization methods: cementation or screw retention. Both methods have been clinically and longterm use proved. However, the advantages and disadvantages of these methods are discussed among physicians. Periodontal examination and proper diagnosis are essential for intelligent treatment. The first step in periodontal diagnosis is to diagnose the disease. Probing around the implants is part of the examination and diagnosis $[170,171]$. Then, the type, extent, and severity of the disease are determined with the help of various indexes, and at the end, it is time to identify the underlying pathological processes and their cause. Complete probing of periodontal pockets and measuring the depth of probing before, during and after treatment is essential for the diagnosis and monitoring of periodontal disease. In the present study, various clinical parameters such as BOP, PD, GR, and CAL were investigated. Probing is one of the most important and reliable parameters in the long-term examination of the soft tissue of the implant [171-174]. Prospective studies also emphasize that, like natural teeth, lack of blood during probing has a high negative predictive value and can be an indicator to predict the stability of the tissues around the implant. The clinical picture that distinguishes periodontitis from gingivitis is the presence of clinically detectable attachment loss in the periodontium. This condition is usually accompanied by the formation of a pocket and changes in the density and height of the adjacent alveolar bone. In some cases, gingival resorption may occur with attachment loss. Therefore, if PD is measured without CAL measurement, the progressive disease remains hidden and undiagnosed [175].

One of the risk factors for periodontal disease is mainly Gram-negative bacteria. Periodontal pathogens that have attracted the most attention of researchers in recent years include $P$. gingivalis, $T$. denticola, and $P$. intermedia. There is evidence that these bacteria are responsible for, or in some way related to, the attachment loss, especially in periodontitis. Evidence suggests that other microorganisms may also be involved in periodontitis. Although these pathogens are necessary for periodontitis, their presence is not sufficient for this purpose [176].

\section{Conclusion}

Today's knowledge states that maintaining soft tissue health is as important in the long-term maintenance and success of implants as osseointegration. Proper maintenance around the implant should be an important motivation for the dentist and the patient to prevent the disease, and this maintenance requires a series of knowledge about the causes of the disease. Usual maintenance of the tissues around the implant is vital but may be difficult for some patients. In this case, a reliable method in periodontal health should be used to prevent the effect of primary microbial accumulation on dental implants. In the present article, it is believed that, to minimize periodontal infections around fixed prosthetic restorations, physicians should be fully aware of the various microbial components and periodontal parameters $[177,178]$.

\section{Future Direction}

Although not new, dental implant procedure is considered a novel treatment in restoring missed teeth. As a progressing field in dentistry, more studies are required for establishing standards regarding peri-implant diseases, correct diagnosis, coherent and evidence-based approach toward treatment of these disease, recognition of the differences between implant restorations and natural teeth, prosthetic driven implant surgery for achieving the most natural design of the lost tooth, and finally developing more biocompatible cements to preserve the tissue and to prevent any peri-implant diseases in cases of cement excess. These are all factors for respecting oral biology, the only one defensive barrier that does not allow us to invade the oral natural structure.

\section{Data Availability}

The data used to support the findings of this study are available from the corresponding author upon request.

\section{Conflicts of Interest}

The authors declare no conflicts of interest. 


\section{Acknowledgments}

The authors would like to thank the colleagues.

\section{References}

[1] P. P. Hujoel and P. Lingström, "Nutrition, dental caries and periodontal disease: a narrative review," Journal of Clinical Periodontology, vol. 44, pp. S79-S84, 2017.

[2] M. Yazdanian, B. Armoon, A. Noroozi et al., "Dental caries and periodontal disease among people who use drugs: a systematic review and meta-analysis," BMC Oral Health, vol. 20 , no. 1, pp. 44-18, 2020.

[3] A. M. Valm, "The structure of dental plaque microbial communities in the transition from health to dental caries and periodontal disease," Journal of Molecular Biology, vol. 431, no. 16, pp. 2957-2969, 2019.

[4] S. P. Goh, D. M. Goh, and E. R. Vickers, "Clinical assessment of a pharmaceutical polyphenol fruit extract gel to inhibit dental plaque," Pharmacology \& Pharmacy, vol. 12, no. 9, pp. 177-189, 2021.

[5] M. A. Curtis, P. I. Diaz, and T. E. D. Van, "The role of the microbiota in periodontal disease," Periodontology, vol. 83, no. 1, pp. 14-25, 2000.

[6] G. Hajishengallis and R. J. Lamont, "Polymicrobial communities in periodontal disease: their quasi-organismal nature and dialogue with the host," Periodontology 2000, vol. 86, no. 1, pp. 210-230, 2021.

[7] Y. Ciçek, R. Orbak, A. Tezel, Z. Orbak, and K. Erciyas, "Effect of tongue brushing on oral malodor in adolescents," Pediatrics International: Official Journal of the Japan Pediatric Society, vol. 45, no. 6, pp. 719-723, 2003.

[8] H. K. Kissov, B. P. Todorova, and E. V. Popova, "Correlation between overcontouring of fixed prosthetic constructions and accumulation of dental plaque," Folia Medica, vol. 43, no. 1-2, pp. 80-83, 2001.

[9] N. A. Valente and S. Andreana, "Peri-implant disease: what we know and what we need to know," Journal of Periodontal \& Implant Science, vol. 46, no. 3, pp. 136-151, 2016.

[10] H. Hirooka and S. Renvert, "Diagnosis of periimplant disease," Implant Dentistry, vol. 28, no. 2, pp. 144-149, 2019.

[11] S. Jepsen, T. Berglundh, R. Genco et al., "Primary prevention of peri-implantitis: managing peri-implant mucositis," Journal of Clinical Periodontology, vol. 42, no. Suppl 16, pp. S152-S157, 2015.

[12] M. Wada, T. Mameno, M. Otsuki, M. Kani, Y. Tsujioka, and K. Ikebe, "Prevalence and risk indicators for peri-implant diseases: a literature review," Japanese Dental Science Review, vol. 57, pp. 78-84, 2021.

[13] M. Umeda, C. Chen, I. Bakker, A. Contreras, J. L. Morrison, and J. Slots, "Risk indicators for harboring periodontal pathogens," Journal of Periodontology, vol. 69, no. 10, pp. 1111-1118, 1998.

[14] J. Slots and M. A. Listgarten, "Bacteroides gingivalis, Bacteroides intermedius and Actinobacillus actinomycetemcomitans in human periodontal diseases," Journal of Clinical Periodontology, vol. 15, no. 2, pp. 85-93, 1988.

[15] S. G. Kancyper and S. Koka, "The influence of intracrevicular crown margins on gingival health: preliminary findings," The Journal of Prosthetic Dentistry, vol. 85, no. 5, pp. 461-465, 2001.

[16] P. Saravanakumar, P. T. Veeravalli, V A. Kumar, K. Mohamed, U. Mani, and M. T. Grover, "Effect of different crown materials on the InterLeukin-one beta content of gingival crevicular fluid in endodontically treated molars: an original research," Cureus, vol. 9, no. 6, Article ID e1361, 2017.

[17] N. Aboelsaad, M. Rayyan, and B. S. Osman, "An update on the effect of crown margin locations and materials on periodontal health," Egyptian Dental Journal, vol. 58, no. 4, 2012.

[18] S. Jamal, R. Ghafoor, F. R. Khan, and K. Zafar, "Five year evaluation of the complications observed in porcelain fused to metal (PFM) crowns placed at a university hospital," JPMA. The Journal of the Pakistan Medical Association, vol. 70, no. 5, pp. 845-850, 2020.

[19] T. E. Donovan and E. J. Swift Jr, "Porcelain-fused-to-metal (pfm) alternatives," Journal of Esthetic and Restorative Dentistry, vol. 21, no. 1, pp. 4-6, 2009.

[20] K. Quante, K. Ludwig, and M. Kern, "Marginal and internal fit of metal-ceramic crowns fabricated with a new laser melting technology," Dental Materials, vol. 24, no. 10, pp. 1311-1315, 2008.

[21] P. S. Ganesh, Review of Dental Crowns and Their Wear Testing, Southern Illinois University at Carbondale, Illinois, USA, 2020.

[22] E. Kontonasaki, P. Giasimakopoulos, and A. E. Rigos, "Strength and aging resistance of monolithic zirconia: an update to current knowledge," Japanese Dental Science Review, vol. 56, no. 1, pp. 1-23, 2020.

[23] F. Tabatabaian, "Color aspect of monolithic zirconia restorations: a review of the literature," Journal of Prosthodontics, vol. 28, no. 3, pp. 276-287, 2019.

[24] J. F. U. Esquivel, M. J. Kim, S. M. Hsu et al., "Randomized clinical study of wear of enamel antagonists against polished monolithic zirconia crowns," Journal of Dentistry, vol. 68, pp. 19-27, 2018.

[25] H. Kim and S. Kim, "Effect of hydrothermal aging on the optical properties of precolored dental monolithic zirconia ceramics," The Journal of Prosthetic Dentistry, vol. 121, no. 4, pp. 676-682, 2019.

[26] R. Izamshah and M. S. Kasim, "Surface roughness analysis of zirconia dental restoration manufactured through $\mathrm{CNC}$ milling machine," in Proceedings of the 2nd Symposium on Intelligent Manufacturing and Mechatronics-SympoSIMM, Springer, Melaka, Malaysia, July 2019.

[27] I. Konstantinidis, D. Trikka, S. Gasparatos, and M. Mitsias, "Clinical outcomes of monolithic zirconia crowns with CAD/CAM technology. a 1-year follow-up prospective clinical study of 65 patients," International Journal of Environmental Research and Public Health, vol. 15, no. 11, 2018.

[28] F. R. Homsy, E. Daou, M. Ghotmi, and M. Rahi, "Self adhesive cements and all ceramic crowns: a review," International Arab Journal of Dentistry, vol. 5, no. 2, 2014.

[29] K. X. Michalakis, H. Hirayama, and P. D. Garefis, "Cementretained versus screw-retained implant restorations: a critical review," The International Journal of Oral \& Maxillofacial Implants, vol. 18, 2003.

[30] K. C. Oh, J.-H. Kim, C.-W. Woo, and H. S. Moon, “Accuracy of customized prefabricated screw-type immediate provisional restorations after single-implant placement," Journal of Clinical Medicine, vol. 8, no. 4, 2019.

[31] T. Mundt, F. Mack, C. Schwahn, and R. Biffar, "Private practice results of screw-type tapered implants: survival and evaluation of risk factors," The International Journal of Oral \& Maxillofacial Implants, vol. 21, 2006.

[32] Y. Y. Tajiri, A. Mine, H. Nakatani et al., "MDP is effective for removing residual polycarboxylate temporary cement as an 
adhesion inhibitor," Dental Materials Journal, vol. 39, no. 6, 2020.

[33] J. L. R. Román, D. M. Millan, A. F. Fons, R. P. Agustín, and L. E. Fernández, "Traction test of temporary dental cements," Journal of clinical and experimental dentistry, vol. 9, no. 4, 2017.

[34] C. E. P. Silva, S. Soares, C. M. Machado et al., "Effect of CAD/ CAM abutment height and cement type on the retention of zirconia crowns," Implant Dentistry, vol. 27, no. 5, pp. 582-587, 2018.

[35] C. Ongthiemsak, T. Mekayarajjananonth, S. Winkler, and K. G. Boberick, "The effect of compressive cyclic loading on retention of a temporary cement used with implants," Journal of Oral Implantology, vol. 31, no. 3, pp. 115-120, 2005.

[36] M. J. Gervais and P. R. Wilson, "A rationale for retrievability of fixed, implant-supported prostheses: a complicationbased analysis," International Journal of Prosthodontics, vol. 20, no. 1, pp. 13-24, 2007.

[37] Y. Oshida, E. B. Tuna, O. Aktören, and K. Gençay, "Dental implant systems," International Journal of Molecular Sciences, vol. 11, no. 4, pp. 1580-1678, 2010.

[38] D. Bartlett and P. A. Brunton, Aesthetic Dentistry, Quintessence Publishing Company Limited, New Malden, England, 2019.

[39] J. L. Sheets, C. Wilcox, and T. Wilwerding, "Cement selection for cement-retained crown technique with dental implants," Journal of Prosthodontics, vol. 17, no. 2, pp. 92-96, 2008.

[40] A. G. Heboyan, A. R. Vardanyan, and A. A. Avetisyan, "Cement selection in dental practice," World Science, vol. 2, 2019.

[41] K. J. Yee and S. Mitha, "Intermediate restorative materials," https://www.slideshare.net/UDDent/intermediaterestorative-materials.

[42] J. Lalithamma, V. Shenoy, E. Kunnamkumarath, P. Paul, J. G. Alapatt, and G. M. Noxy, "Evaluation of temporization period with zinc oxide eugenol and non-eugenol cement on bond strength of self-adhesive dual-cure resin cement," International Journal of Oral Care and Research, vol. 6, no. 1, 2018.

[43] C. Mehl, S. Harder, M. Wolfart, M. Kern, and S. Wolfart, "Retrievability of implant-retained crowns following cementation," Clinical Oral Implants Research, vol. 19, no. 12, pp. 1304-1311, 2008.

[44] M. Korsch, S.-M. Marten, W. Walther, M. Vital, D. H. Pieper, and A. Dötsch, "Impact of dental cement on the peri-implant biofilm-microbial comparison of two different cements in an in vivo observational study," Clinical Implant Dentistry and Related Research, vol. 20, no. 5, pp. 806-813, 2018.

[45] T. R. Schoenbaum, Y. Y. Chang, and P. R. Klokkevold, "Screw-access marking: a technique to simplify retrieval of cement-retained implant prostheses," Compendium of continuing education in dentistry (Jamesburg, NJ: 1995), vol. 34, no. 3, pp. 230-236, 2013.

[46] B. R. Merz, S. Hunenbart, and U. C. Belser, "Mechanics of the implant-abutment connection: an 8-degree taper compared to a butt joint connection," The International Journal of Oral \& Maxillofacial Implants, vol. 15, no. 4, pp. 519-526, 2000.

[47] S. Ma and A. Fenton, "Screw- versus cement-retained implant prostheses: a systematic review of prosthodontic maintenance and complications," International Journal of Prosthodontics, vol. 28, no. 2, pp. 127-145, 2015.
[48] N. Almehmadi, A. Kutkut, and M. Al-Sabbagh, "What is the best available luting agent for implant prosthesis?" Dental Clinics of North America, vol. 63, no. 3, pp. 531-545, 2019.

[49] K. Akça, H. Iplikçioğlu, and M. C. Cehreli, "Comparison of uniaxial resistance forces of cements used with implantsupported crowns," The International Journal of Oral \& Maxillofacial Implants, vol. 17, no. 4, pp. 536-542, 2002.

[50] A. Mansour, C. Ercoli, G. Graser, R. Tallents, and M. Moss, "Comparative evaluation of casting retention using the ITI solid abutment with six cements," Clinical Oral Implants Research, vol. 13, no. 4, pp. 343-348, 2002.

[51] J. G. Wittneben, C. Millen, and U. Brägger, "Clinical performance of screw- versus cement-retained fixed implantsupported reconstructions--a systematic review," The International Journal of Oral \& Maxillofacial Implants.vol. 29, no. Suppl, pp. 84-98, 2014.

[52] M. Khoroushi and F. Keshani, "A review of glass-ionomers: from conventional glass-ionomer to bioactive glass-ionomer," Dental Research Journal, vol. 10, no. 4, 2013.

[53] S. Gurgan, Z. B. Kutuk, and E. Ergin, "A randomized controlled 10 years follow up of a glass ionomer restorative material in class I and class II cavities," Journal of Dentistry, vol. 94, Article ID 103175, 2020.

[54] D. McComb, R. L. Erickson, W. G. Maxymiw, and R. E. Wood, "A clinical comparison of glass ionomer, resinmodified glass ionomer and resin composite restorations in the treatment of cervical caries in xerostomic head and neck radiation patients," Operative Dentistry, vol. 27, no. 5, pp. 430-437, 2002.

[55] S. Gurgan, Z. B. Kutuk, E. Ergin, S. S. Oztas, and F. Y. Cakir, "Clinical performance of a glass ionomer restorative system: a 6-year evaluation," Clinical Oral Investigations, vol. 21, no. 7, pp. 2335-2343, 2017.

[56] M. S. Baig and G. J. P. Fleming, "Conventional glass-ionomer materials: a review of the developments in glass powder, polyacid liquid and the strategies of reinforcement,"Journal of Dentistry, vol. 43, no. 8, pp. 897-912, 2015.

[57] W. Bakhadher, "Modification of glass ionomer restorative material: a review of literature," EC Dental Science, vol. 18, pp. 1001-1006, 2019.

[58] T. M. Hafshejani, A. Zamanian, J. R. Venugopal et al., "Antibacterial glass-ionomer cement restorative materials: a critical review on the current status of extended release formulations," Journal of Controlled Release, vol. 262, pp. 317-328, 2017.

[59] B. G. Bernal, J. E. Elizondo, N. C. Fierro et al., "Paediatric dentistry: glass ionomer or giomer?," 2021, https://www. oraljournal.com/pdf/2021/vol7issue3/PartB/7-3-12-543.pdf.

[60] M. S. Hagge, R. D. M. Wong, and J. S. Lindemuth, "Retention strengths of five luting cements on prefabricated dowels after root canal obturation with a zinc oxide/eugenol sealer: 1 . Dowel space preparation/cementation at one week after obturation," Journal of Prosthodontics, vol. 11, no. 3, pp. 168-175, 2002.

[61] N. Chezhian, D. Ganapathy, and A. R. Jain, "Resin luting agents-A review,” Drug Invention Today, vol. 10, 2018.

[62] H. Yu, M. Zheng, R. Chen, and H. Cheng, "Proper selection of contemporary dental cements," Oral health and dental management, vol. 13, no. 1, pp. 54-59, 2014.

[63] K. Wingo, "A review of dental cements," Journal of Veterinary Dentistry, vol. 35, no. 1, pp. 18-27, 2018.

[64] D. Chellappa and A. Thangavel, "Protecting pulpal health: a restorative perspective," Endodontic Practice Today, vol. 13, no. 4, 2019. 
[65] E. E. Hill, "Dental cements for definitive luting: a review and practical clinical considerations," Dental Clinics of North America, vol. 51, no. 3, pp. 643-658, 2007.

[66] S. AlZain, "Effect of home bleaching on surface of zinc phosphate cement: a scanning electron microscopic study," Nigerian Journal of Clinical Practice, vol. 21, no. 6, pp. 807-811, 2018.

[67] M. Behr, M. Rosentritt, J. Wimmer et al., "Self-adhesive resin cement versus zinc phosphate luting material: a prospective clinical trial begun 2003," Dental Materials, vol. 25, no. 5, pp. 601-604, 2009.

[68] P. R. Kachalia, "Ceramic materials in implant dentistry," Evidence-based Implant Treatment Planning and Clinical Protocols, vol. 123, 2016.

[69] D. Flanagan, "Zinc phosphate as a definitive cement for implant-supported crowns and fixed dentures," Clinical, Cosmetic and Investigational Dentistry, vol. 9, pp. 93-97, 2017.

[70] Leonhardt, T. Berglundh, I. Ericsson, and G. Dahlen, "Putative periodontal and teeth in pathogens on titanium implants and teeth in experimental gingivitis and periodontitis in beagle dogs," Clinical Oral Implants Research, vol. 3, no. 3, pp. 112-119, 1992.

[71] R. Pontoriero, M. P. Tonelli, G. Carnevale, A. Mombelli, S. R. Nyman, and N. P. Lang, "Experimentally induced periimplant mucositis. A clinical study in humans," Clinical Oral Implants Research, vol. 5, no. 4, pp. 254-259, 1994.

[72] G. E. Salvi, M. Aglietta, S. Eick, A. Sculean, N. P. Lang, and C. A. Ramseier, "Reversibility of experimental peri-implant mucositis compared with experimental gingivitis in humans," Clinical Oral Implants Research, vol. 23, no. 2, pp. 182-190, 2012.

[73] N. P. Lang, D. D. Bosshardt, and M. Lulic, "Do mucositis lesions around implants differ from gingivitis lesions around teeth?" Journal of Clinical Periodontology, vol. 38, no. Suppl 11, pp. 182-187, 2011.

[74] A. M. Roos-Jansåker, H. Renvert, C. Lindahl, and S. Renvert, "Nine- to fourteen-year follow-up of implant treatment. Part III: factors associated with peri-implant lesions," Journal of Clinical Periodontology, vol. 33, no. 4, pp. 296-301, 2006.

[75] O. C. Koldsland, A. A. Scheie, and A. M. Aass, "The association between selected risk indicators and severity of periimplantitis using mixed model analyses," Journal of Clinical Periodontology, vol. 38, no. 3, pp. 285-292, 2011.

[76] L. Chambrone, L. A. Chambrone, and L. A. Lima, "Effects of occlusal overload on peri-implant tissue health: a systematic review of animal-model studies," Journal of Periodontology, vol. 81, no. 10, pp. 1367-1378, 2010.

[77] A. Kozlovsky, H. Tal, B.-Z. Laufer et al., "Impact of implant overloading on the peri-implant bone in inflamed and noninflamed peri-implant mucosa," Clinical Oral Implants Research, vol. 18, no. 5, pp. 601-610, 2007.

[78] B. E. Pjetursson, D. Thoma, R. Jung, M. Zwahlen, and A. Zembic, "A systematic review of the survival and complication rates of implant-supported fixed dental prostheses (FDPs) after a mean observation period of at least 5 years," Clinical Oral Implants Research, vol. 23, no. Suppl 6, pp. 22-38, 2012.

[79] L. J. A. Heitz-Mayfield, "Peri-implant diseases: diagnosis and risk indicators," Journal of Clinical Periodontology, vol. 35, no. 8 Suppl, pp. 292-304, 2008.

[80] S. Renvert, G. R. Persson, F. Q. Pirih, and P. M. Camargo, "Peri-implant health, peri-implant mucositis, and periimplantitis: case definitions and diagnostic considerations,"
Journal of Clinical Periodontology, vol. 45, no. Suppl 20, pp. S278-S285, 2018.

[81] S. Renvert, G. R. Persson, F. Q. Pirih, and P. M. Camargo, "Peri-implant health, peri-implant mucositis, and periimplantitis: case definitions and diagnostic considerations," Journal of Periodontology, vol. 89, no. Suppl 1, pp. S304S312, 2018.

[82] T. Berglundh, G. Armitage, M. G. Araujo et al., "Peri-implant diseases and conditions: consensus report of workgroup 4 of the 2017 World Workshop on the classification of periodontal and peri-implant diseases and conditions," Journal of Clinical Periodontology, vol. 45, no. Suppl 20, pp. S286S291, 2018.

[83] M. A. Weinberg and H. Hassan, "Bleeding on probing: what does it mean?” General Dentistry, vol. 60, no. 4, pp. 271-276, 2012.

[84] C. A. Ramseier, D. Mirra, C. Schütz et al., "Bleeding on probing as it relates to smoking status in patients enrolled in supportive periodontal therapy for at least 5 years," Journal of Clinical Periodontology, vol. 42, no. 2, pp. 150-159, 2015.

[85] L. Checchi, M. Montevecchi, V. Checchi, and F. Zappulla, "The relationship between bleeding on probing and subgingival deposits. An endoscopical evaluation," The Open Dentistry Journal, vol. 3, no. 1, pp. 154-160, 2009.

[86] D. Hashim, N. Cionca, C. Combescure, and A. Mombelli, "The diagnosis of peri-implantitis: a systematic review on the predictive value of bleeding on probing," Clinical Oral Implants Research, vol. 29, no. S16, pp. 276-293, 2018.

[87] R. Farina, M. Filippi, J. Brazzioli, C. Tomasi, and L. Trombelli, "Bleeding on probing around dental implants: a retrospective study of associated factors," Journal of Clinical Periodontology, vol. 44, no. 1, pp. 115-122, 2017.

[88] J. Schrodi, L. Recio, J. Fiorellini, H. Howell, M. Goodson, and N. Karimbux, "The effect of aspirin on the periodontal parameter bleeding on probing," Journal of Periodontology, vol. 73, no. 8, pp. 871-876, 2002.

[89] V. Muñoz, A. Duque, A. Giraldo, and R. Manrique, "Prevalence of peri-implant disease according to periodontal probing depth and bleeding on probing: a systematic review and meta-analysis," The International Journal of Oral \& Maxillofacial Implants, vol. 33, no. 4, 2018.

[90] C. A. Ramseier, J. R. Fischer, G. Fischer, and M. Schimmel, "Effect of age on bleeding on probing (BOP) as an indicator of periodontal inflammation in patients enrolled in supportive periodontal therapy," Oral Health \& Preventive Dentistry, vol. 19, pp. 43-50, 2021.

[91] S. Luterbacher, L. Mayfield, U. Brägger, and N. P. Lang, "Diagnostic characteristics of clinical and microbiological tests for monitoring periodontal and peri-implant mucosal tissue conditions during supportive periodontal therapy (SPT)," Clinical Oral Implants Research, vol. 11, no. 6, pp. 521-529, 2000.

[92] S. Renvert, C. Lindahl, and G. R. Persson, "Occurrence of cases with peri-implant mucositis or peri-implantitis in a 2126 years follow-up study," Journal of Clinical Periodontology, vol. 45, no. 2, pp. 233-240, 2018.

[93] R. Teles, K. Moss, J. S. Preisser et al., "Patterns of periodontal disease progression based on linear mixed models of clinical attachment loss," Journal of Clinical Periodontology, vol. 45, no. 1, pp. 15-25, 2018.

[94] K. Collares, F. F. Demarco, B. L. Horta, and M. B. Correa, "Proximal restoration increases the risk of clinical attachment loss," Journal of Clinical Periodontology, vol. 45, no. 7, pp. 832-840, 2018. 
[95] C. Manau, A. Echeverria, A. Agueda, A. Guerrero, and J. J. Echeverria, "Periodontal disease definition may determine the association between periodontitis and pregnancy outcomes," Journal of Clinical Periodontology, vol. 35, no. 5, pp. 385-397, 2008.

[96] M. De Sanctis, N. Baldini, and F. Vignoletti, "Biological width around implants," Journal de Parodontologie \& d'Implantologie Orale.vol. 29, no. 4, 2010.

[97] J. D. Beck and S. Offenbacher, "Relationships among clinical measures of periodontal disease and their associations with systemic markers," Annals of Periodontology, vol. 7, no. 1, pp. 79-89, 2002.

[98] G. C. Armitage, "The complete periodontal examination," Periodontology 2000, vol. 34, no. 1, pp. 22-33, 2004.

[99] B. Holtfreter, D. Alte, C. Schwahn, M. Desvarieux, and T. Kocher, "Effects of different manual periodontal probes on periodontal measurements," Journal of Clinical Periodontology, vol. 39, no. 11, pp. 1032-1041, 2012.

[100] A. D. Mitic, J. Z. Gasic, R. G. Barac et al., "Ultrastructural changes in the cemento-enamel junction caused by acidic beverages: an in vitro study," Microscopy Research and Technique, vol. 83, no. 2, pp. 91-98, 2020.

[101] P. J. Pérez-Chaparro, J. A. McCulloch, E. M. Mamizuka et al., "Do different probing depths exhibit striking differences in microbial profiles?" Journal of Clinical Periodontology, vol. 45, no. 1, pp. 26-37, 2018.

[102] S. E. Yang, A. R. Jo, H. J. Lee, and S. Y. Kim, "Analysis of the characteristics of cracked teeth and evaluation of pulp status according to periodontal probing depth," BMC Oral Health, vol. 17, no. 1, pp. 135-136, 2017.

[103] I. L. C. Chapple, B. L. Mealey, T. E. D. Van et al., "Periodontal health and gingival diseases and conditions on an intact and a reduced periodontium: consensus report of workgroup 1 of the 2017 World Workshop on the Classification of Periodontal and Peri-Implant Diseases and Conditions," Journal of Periodontology, vol. 89, pp. S74-S84, 2018.

[104] M. Chen, H. Yin, H. Chang, C. Kao, C. Tu, and Y. Chen, "Baseline probing depth and interproximal sites predict treatment outcomes of non-surgical periodontal therapy," Journal of dental sciences, vol. 15, no. 1, pp. 50-58, 2020.

[105] V. Krishnan, R. Ambili, Z. Davidovitch, and N. C. Murphy, "Gingiva and orthodontic treatment," Seminars in Orthodontics, vol. 13, no. 4, 2007.

[106] A. Ramanauskaite and G. Juodzbalys, "Diagnostic principles of peri-implantitis: a systematic review and guidelines for peri-implantitis diagnosis proposal," Journal of Oral \& Maxillofacial Research, vol. 7, no. 3, pp. e8-e, 2016.

[107] G. Serino, A. Turri, and N. P. Lang, "Probing at implants with peri-implantitis and its relation to clinical peri-implant bone loss," Clinical Oral Implants Research, vol. 24, no. 1, pp. 91-95, 2013.

[108] N. U. Zitzmann and T. Berglundh, "Definition and prevalence of peri-implant diseases," Journal of Clinical Periodontology, vol. 35, no. 8 Suppl, pp. 286-291, 2008.

[109] M. Sanz and I. L. Chapple, "Clinical research on peri-implant diseases: consensus report of Working Group 4," Journal of Clinical Periodontology, vol. 39, no. Suppl 12, pp. 202-206, 2012.

[110] "Academy report: peri-implant mucositis and peri-implantitis: a current understanding of their diagnoses and clinical implications," Journal of Periodontology, vol. 84, no. 4, pp. 436-443, 2013.

[111] J. Lindhe and J. Meyle, "Peri-implant diseases: consensus report of the sixth European Workshop on Periodontology,"
Journal of Clinical Periodontology, vol. 35, no. 8 Suppl, pp. 282-285, 2008.

[112] S. J. Froum and P. S. Rosen, "A proposed classification for peri-implantitis," The International Journal of Periodontics \& Restorative Dentistry, vol. 32, no. 5, pp. 533-540, 2012.

[113] F. Schwarz, N. Sahm, I. Mihatovic, V. Golubovic, and J. Becker, "Surgical therapy of advanced ligature-induced peri-implantitis defects: cone-beam computed tomographic and histological analysis," Journal of Clinical Periodontology, vol. 38, no. 10, pp. 939-949, 2011.

[114] W. Zhou, C. Han, D. Li, Y. Li, Y. Song, and Y. Zhao, "Endodontic treatment of teeth induces retrograde periimplantitis," Clinical Oral Implants Research, vol. 20, no. 12, pp. 1326-1332, 2009.

[115] H.-L. Chan, H.-L. Wang, J. D. Bashutski, P. C. Edwards, J.-H. Fu, and T.-J. Oh, "Retrograde peri-implantitis: a case report introducing an approach to its management," Journal of Periodontology, vol. 82, no. 7, pp. 1080-1088, 2011.

[116] M. Dominiak and T. Gedrange, "New perspectives in the diagnostic of gingival recession Advances in clinical and experimental medicine," Advances in Clinical and Experimental Medicine, vol. 23, no. 6, pp. 857-863, 2014.

[117] O. Osadolor, E. Akaji, N. Onyejaka, and A. Osadolor, "Gingival recession in a rural community in Nigeria: a pilot study," IOSR Journal of Dental and Medical Science, vol. 18, no. 4, pp. 18-21, 2019.

[118] S. Shakya, S. Pradhan, R. S. Gorkhali, M. Giri, K. Sushil, and S. Gupta, "Prevalence and aetiology of gingival recession in mandibular anterior teeth," JNDA, vol. 17, 2017.

[119] I. Fragkioudakis, D. Tassou, M. Sideri, and I. Vouros, "Prevalance and clinical characteristics of gingival recession in greek young adults: a cross-sectional study," Clinical and Experimental Dental Research, vol. 7, 2021.

[120] M. A. Banglani, M. Panhwar, S. K. Punjabi, and K. Memon, "Assessment of gingival recession among adolescent of Jamshoro city," The Professional Medical Journal, vol. 26, no. 9, pp. 1427-1433, 2019.

[121] J. W. Morris, P. M. Campbell, L. P. Tadlock, J. Boley, and P. H. Buschang, "Prevalence of gingival recession after orthodontic tooth movements," American Journal of Orthodontics and Dentofacial Orthopedics, vol. 151, no. 5, pp. 851-859, 2017.

[122] A. Kasaj, Gingival Recession Management, Springer, Berlin, Germany, 2018.

[123] S. A. Finkleman and B. Bayirli, "Prevalence of gingival recession after orthodontic tooth movements," American Journal of Orthodontics and Dentofacial Orthopedics, vol. 153, no. 5, 2018.

[124] A. Kasaj, "Etiology and prevalence of gingival recession," in Gingival Recession ManagementSpringer, Berlin, Germany, 2018.

[125] S. Ravipudi, D. Appukuttan, P. Prakash, and D. Victor, "Gingival recession: short literature review on etiology, classifications and various treatment options," Journal of Pharmaceutical Sciences and Research, vol. 9, no. 2, 2017.

[126] P. M. B. P. S. Tróia, T. R. Spuldaro, P. A. B. D. Fonseca, and G. V. D. O. Fernandes, "Presence of gingival recession or noncarious cervical lesions on teeth under occlusal trauma: a systematic review," European Journal of General Dentistry, vol. 10, 2021.

[127] M. Kocar, K. Seme, and N. I. Hren, "Characterization of the normal bacterial flora in peri-implant sulci of partially and completely edentulous patients," The International Journal of 
Oral \& Maxillofacial Implants, vol. 25, no. 4, pp. 690-698, 2010.

[128] M. Albertini, L. López-Cerero, M. G. O’Sullivan et al., "Assessment of periodontal and opportunistic flora in patients with peri-implantitis," Clinical Oral Implants Research, vol. 26, no. 8, pp. 937-941, 2015.

[129] S. Eick, C. A. Ramseier, K. Rothenberger, U. Brägger, D. Buser, and G. E. Salvi, "Microbiota at teeth and implants in partially edentulous patients. A 10-year retrospective study," Clinical Oral Implants Research, vol. 27, no. 2, pp. 218-225, 2016.

[130] W. Xu, W. Zhou, H. Wang, and S. Liang, "Roles of Porphyromonas gingivalis and its virulence factors in periodontitis," Advances in protein chemistry and structural biology, vol. 120, pp. 45-84, 2020.

[131] T. R. Mikuls, J. B. Payne, R. A. Reinhardt et al., "Antibody responses to Porphyromonas gingivalis (P. gingivalis) in subjects with rheumatoid arthritis and periodontitis," International Immunopharmacology, vol. 9, no. 1, pp. 38-42, 2009.

[132] I. Olsen and Ö. Yilmaz, "Possible role of Porphyromonas gingivalis in orodigestive cancers," Journal of Oral Microbiology, vol. 11, no. 1, Article ID 1563410, 2019.

[133] K. Sato, N. Takahashi, T. Kato et al., "Aggravation of collagen-induced arthritis by orally administered Porphyromonas gingivalis through modulation of the gut microbiota and gut immune system," Scientific Reports, vol. 7, no. 1, pp. 6955-7013, 2017.

[134] J. Y. Jang, K. J. Baek, Y. Choi, and S. Ji, "Relatively low invasive capacity of Porphyromonas gingivalis strains into human gingival fibroblasts in vitro," Archives of Oral Biology, vol. 83, pp. 265-271, 2017.

[135] K. Y. How, K. P. Song, and K. G. Chan, "Porphyromonas gingivalis: an overview of periodontopathic pathogen below the gum line," Frontiers in Microbiology, vol. 7, 2016.

[136] I. Olsen, J. D. Lambris, and G. Hajishengallis, "Porphyromonas gingivalis disturbs host-commensal homeostasis by changing complement function," Journal of Oral Microbiology, vol. 9, no. 1, Article ID 1340085, 2017.

[137] K. Maeda, H. Nagata, Y. Yamamoto et al., "Glyceraldehyde3-phosphate dehydrogenase of Streptococcus oralis functions as a coadhesin for Porphyromonas gingivalis major fimbriae," Infection and Immunity, vol. 72, no. 3, pp. 1341-1348, 2004.

[138] Y. Sun, R. Shu, C. Li, and M.-Z. Zhang, "Gram-negative periodontal bacteria induce the activation of toll-like receptors 2 and 4, and cytokine production in human periodontal ligament cells," Journal of Periodontology, vol. 81, no. 10, pp. 1488-1496, 2010.

[139] T. D. Herath, Y. Wang, C. J. Seneviratne, R. P. Darveau, C. Y. Wang, and L. Jin, "The expression and regulation of matrix metalloproteinase- 3 is critically modulated by Porphyromonas gingivalis lipopolysaccharide with heterogeneous lipid A structures in human gingival fibroblasts," BMC Microbiology, vol. 13, no. 1, pp. 73-12, 2013.

[140] B. Chi, M. Qi, and H. K. Kuramitsu, "Role of dentilisin in Treponema denticola epithelial cell layer penetration," Research in Microbiology, vol. 154, no. 9, pp. 637-643, 2003.

[141] F. Foschi, J. Izard, H. Sasaki et al., "Treponema denticola in disseminating endodontic infections," Journal of Dental Research, vol. 85, no. 8, pp. 761-765, 2006.

[142] R. K. Verma, S. Rajapakse, A. Meka, C. Hamrick, S. Pola, and I. Bhattacharyya, "Porphyromonas gingivalis and Treponema denticola mixed microbial infection in a rat model of periodontal disease," Interdisciplinary perspectives on infectious diseases, vol. 2010, Article ID 605125, 10 pages, 2010.

[143] L. Scapoli, A. Girardi, A. Palmieri et al., "Microflora and periodontal disease," Dental Research Journal, vol. 9, no. Suppl 2, 2012.

[144] F. Carinci, L. Scapoli, A. Girardi et al., "Oral microflora and periodontal disease: new technology for diagnosis in dentistry," Annali di Stomatologia, vol. 4, no. 2, 2013.

[145] P. M. N. D. Lima and R do, A. L. Palma, A. A. Hasna, R. D. Rossoni, J. C. Junqueira, and L. D. D. Oliveira, The periodontal pathogen Treponema denticola: an atherosclerosis risk factor," Research, Society and Development, vol. 10, no. 1, Article ID e25810111637, 2021.

[146] P. Emecen-Huja, R. J. Danaher, D. R. Dawson et al., "Relationship between herpesviruses and periodontal disease progression," Journal of Clinical Periodontology, vol. 47, no. 4, pp. 442-450, 2020.

[147] H. M. Ng, N. Slakeski, C. A. Butler et al., "The role of treponema denticola motility in synergistic biofilm formation with porphyromonas gingivalis," Frontiers in cellular and infection microbiology, vol. 9, 2019.

[148] H.-K. Jun, Y.-J. Jung, and B.-K. Choi, “Treponema denticola, Porphyromonas gingivalis, and Tannerella forsythia induce cell death and release of endogenous danger signals," Archives of Oral Biology, vol. 73, pp. 72-78, 2017.

[149] G. Hajishengallis and P. I. Diaz, "Porphyromonas gingivalis: immune subversion activities and role in periodontal dysbiosis," Current oral health reports, vol. 7, no. 1, pp. 12-21, 2020.

[150] D. Listyarifah, M. T. Nieminen, L. K. Mäkinen et al., "Treponema denticolachymotrypsin-like proteinase is present in early-stage mobile tongue squamous cell carcinoma and related to the clinicopathological features," Journal of Oral Pathology \& Medicine, vol. 47, no. 8, pp. 764-772, 2018.

[151] L. Yousefi, H. E. Leylabadlo, T. Pourlak et al., "Oral spirochetes: pathogenic mechanisms in periodontal disease," Microbial Pathogenesis, vol. 144, Article ID 104193, 2020.

[152] M. T. Nieminen, D. Listyarifah, J. Hagström et al., "Treponema denticola chymotrypsin-like proteinase may contribute to orodigestive carcinogenesis through immunomodulation," British Journal of Cancer, vol. 118, no. 3, pp. 428-434, 2018.

[153] A. K. Kylmä, L. Jouhi, D. Listyarifah et al., "Treponema denticola chymotrypsin-like protease as associated with HPV-negative oropharyngeal squamous cell carcinoma," British Journal of Cancer, vol. 119, no. 1, pp. 89-95, 2018.

[154] P. E. Kolenbrander, R. N. Andersen, D. S. Blehert, P. G. Egland, J. S. Foster, and R. J. Palmer, "Communication among oral bacteria," Microbiology and Molecular Biology Reviews, vol. 66, no. 3, pp. 486-505, 2002.

[155] S. F. Poole, A. Pitondo-Silva, M. Oliveira-Silva, I. C. M. Moris, and E. A. Gomes, "Influence of different ceramic materials and surface treatments on the adhesion of Prevotella intermedia," Journal of the Mechanical Behavior of Biomedical Materials, vol. 111, 2020.

[156] R. D. Haigh, L. A. Crawford, J. D. Ralph et al., "Draft wholegenome sequences of periodontal pathobionts Porphyromonas gingivalis, Prevotella intermedia, and Tannerella forsythia contain phase-variable restriction-modification systems," Genome Announcements, vol. 5, no. 46, Article ID e01229, 2017.

[157] M. P. Lopes, Á. A. Cruz, M. T. Xavier et al., "Prevotella intermedia and periodontitis are associated with severe 
asthma," Journal of Periodontology, vol. 91, no. 1, pp. 46-54, 2020.

[158] M. Puletic, B. Popovic, S. Jankovic, and G. Brajovic, "Detection rates of periodontal bacteria and herpesviruses in different forms of periodontal disease," Microbiology and Immunology, vol. 64, no. 12, pp. 815-824, 2020.

[159] P. Dixitraj, A. Nayak, S. Bansal, and K. Bhat, "Detection of antibodies against Prevotella Intermedia in patients with chronic periodontitis and periodontally healthy individuals," Dentistry and Medical Research, vol. 9, no. 1, 2021.

[160] A. Doneta, F. Norina, D. Irina, and R. Natalia, "Interaction of porphyromonas gingivalis bacterium with other bacteria in determining periodontal disease and valid treatments," Romanian Journal of Oral Rehabilitation, vol. 12, no. 2, 2020.

[161] M. Nakagawa, M. Shirasugi, T. Yamamoto, T. Nakaya, and N. Kanamura, "Long-term exposure to butyric acid induces excessive production of matrix metalloproteases in human gingival fibroblasts," Archives of Oral Biology, vol. 123, Article ID 105035, 2021.

[162] M. Guan, L. Shu, . Fu, B. Liu, X. Xu, and J. Wu, "Prevotella intermedia induces matrix metalloproteinase- 9 expression in human periodontal ligament cells," FEMS Microbiology Letters, vol. 283, no. 1, pp. 47-53, 2008.

[163] S.-M. Guan, J.-J. He, M. Zhang, and L. Shu, "Prevotella intermediastimulates tissue-type plasminogen activator and plasminogen activator inhibitor-2 expression via multiple signaling pathways in human periodontal ligament cells," FEMS Immunology and Medical Microbiology, vol. 62, no. 1, pp. 91-100, 2011.

[164] S.-M. Guan, L. Shu, S.-M. Fu, B. Liu, X.-L. Xu, and J.-Z. Wu, "Prevotella intermediaupregulates MMP-1 and MMP-8 expression in human periodontal ligament cells," FEMS Microbiology Letters, vol. 299, no. 2, pp. 214-222, 2009.

[165] A. Nanci and D. D. Bosshardt, "Structure of periodontal tissues in health and disease," Periodontology 2000, vol. 40, no. 1, pp. 11-28, 2006.

[166] Z. Feng and A. Weinberg, "Role of bacteria in health and disease of periodontal tissues," Periodontology 2000, vol. 40, no. 1, pp. 50-76, 2006.

[167] J. Reeves, "Periodontal health - challenges in restorative dentistry," Primary Dental Journal, vol. 3, no. 2, pp. 72-76, 2014.

[168] P. Krishnan, D. Ganapathy, and A. Rhea, "Knowledge of oral hygiene measures in patient with dental implants," Drug Invention Today, vol. 13, no. 3, 2020.

[169] R. Cheraghi, E. Jalalian, F. Rajaei, M. Bavaisi, N. Moghaddam, and F. Keykha, "A comparison between the effect of all-ceramic and metal-ceramic restorations on the plaque accumulation," Journal of Dental Medicine, vol. 28, 2015.

[170] M. Gómez-Polo, R. Ortega, C. Gómez-Polo, A. Celemin, J. D. R. Highsmith, and J. D. R. Highsmith, "Factors affecting the decision to use cemented or screw-retained fixed implant-supported prostheses: a critical review," International Journal of Prosthodontics, vol. 31, no. 1, 2018.

[171] E. Anitua and M. H. Alkhraisat, "Clinical performance of short dental implants supporting single crown restoration in the molar-premolar region: cement versus screw retention," The International Journal of Oral \& Maxillofacial Implants, vol. 34, no. 4, pp. 969-976, 2019.

[172] S. Humphrey, "Implant maintenance," Dental Clinics of North America, vol. 50, no. 3, pp. 463-478, 2006.

[173] S. M. Shaddel, M. Bayat, M. Bayat, M. Bayani, and V. Nazari, "The awareness and attitude of general dentists on dental implants follow-up," Journal of Arak University Medical Sciences, vol. 24, no. 2, pp. 268-277, 2021.

[174] I. I. P. Sites, "Consensus statements and recommended clinical procedures regarding surgical techniques," The International journal of oral \& maxillofacial, vol. 24, 2009.

[175] F. Jalalian and N. Naghsh, "Maintenance care of dental implants: a clinical review," Journal of Isfahan Dental School, vol. 12, no. 4, pp. 457-468, 2017.

[176] F. Q. Bui, C. L. C. D. S. Almeida, B. Huynh et al., "Association between periodontal pathogens and systemic disease," Biomedical Journal, vol. 42, no. 1, pp. 27-35, 2019.

[177] Y. Hao, X. Huang, X. Zhou et al., "Influence of dental prosthesis and restorative materials interface on oral biofilms," International Journal of Molecular Sciences, vol. 19, no. 10, 2018.

[178] S. Elnagdy, M. Raptopoulos, I. Kormas, A. Pedercini, and L. F. Wolff, "Local oral delivery agents with anti-biofilm properties for the treatment of periodontitis and periimplantitis," A Narrative Review. Molecules.vol. 26, no. 18, 2021. 